\title{
Adsorption studies of cyanide onto activated carbon and $y$-alumina impregnated with cooper ions
}

\author{
Liliana Giraldo' ${ }^{1}$, Juan Carlos Moreno-Piraján² \\ ${ }^{1}$ Facultad de Ciencias, Departamento de Química, Universidad Nacional de Colombia, Bogotá, Colombia; lgiraldogu@bt.unal.edu.co; \\ ${ }^{2}$ Facultad de Ciencias, Departamento de Química, Grupo de Investigación en Sólidos Porosos y Calorimetría, Universidad de los \\ Andes, Bogotá, Colombia; jumoreno@uniandes.edu.co.
}

Received 5 May 2010; revised 17 June 2010; accepted 20 June 2010.

\begin{abstract}
In this research, adsorption of cyanide onto catalyst synthesized with activated carbon and yalumina used supported and cooper has been studied by means of batch technique. Percentage adsorption was determined for this catalyst in function of $\mathrm{pH}$, adsorbate concentration and temperature. Adsorption data has been interpreted in terms of Freundlich and Langmuir equations. Thermodynamics parameters for the adsorption system have been determined at three different temperatures.
\end{abstract}

Keywords: Activated carbon; Alumina; Cyanide; Isotherms; Thermodynamic

\section{INTRODUCTION}

Waste water discharged by industrial activities is often contaminated by a variety of toxic or otherwise harmful substances which have negative effects on the water environment. For example, of metal finishing industry and electroplating units is one of the major sources of heavy metals such as $(\mathrm{Zn}, \mathrm{Cu}, \mathrm{Cr}, \mathrm{Pb}$ etc.) and cyanide pollutants which contribute greatly to the pollution load of the receiving water bodies and therefore increase the environmental risk [1-4]. Cyanide present in effluent water of several industries. Cyanidation has dominated the gold mining industry. In view of the toxicity of cyanide, and the fact that cyanide is fatal in small dosages, authorities have been forced to tighten up plant discharge regulations. It is therefore vital to recover as much cyanide as possible, not only to meet standard requirements, but to strive towards obtaining lower levels of free cyanide $(\mathrm{CN}-)$ in tailing and plant effluent [4-8]. The solubility of gold in cyanide solution was recognized as early as 1783 by Scheel (Sweden) and was studied in the 1840s and 1850s by Elkington and Bagration (Russia), Elsner (German) and Faraday (England) [9]. Elkington also had a patent for the use of potassium cyanide solutions for electroplating of gold and silver [9]. Cyanide is a singly-charged anion containing unimolar amounts of carbon and nitrogen atoms triply-bounded together. It is a strong ligand, capable of complexing at low concentrations with virtually any heavy metal. Because the health and survival of plants and animals are dependent on the transport of these heavy metals through their tissues, cyanide is very toxic. Several systems have been adopted for the reduction of cyanide in mill discharges. There are $\mathrm{SO}_{2}$ assisted oxidation, natural degradation, acidification volatilization-reneutralization, oxidation and biological treatment. However, in the first three processes, cyanide reduction does not appear to meet the strict regulatory requirements, and as for the fourth process, it is limited to certain climate conditions. The next best process used, is the oxidation with hydrogen peroxide where the cyanide concentration is reduced to low enough levels, but this process requires an expensive reagent which cannot be reused [10-16]. Activated carbon was used for the removal of free cyanide from solution, but observed that copperimpregnated carbon yielded far better cyanide removal [17]. However, did not test other metal impregnated carbons or different metal loadings on the carbon. The use of a metal impregnated carbon system would therefore be more effective in reducing cyanide concentrations in solution. Due to the problem mentioned above, the study on using activated carbon in the removal of free cyanide is being done in our laboratory $[18,19]$. The adsorption onto activated carbon has found increasing application in the treatment of wastewater, as well as for the recovery of metals from cyanide leached pulps. Activated carbon has a great potential for cyanide waste treatment both in gold extraction plants and effluent from metal finishing plants and hence, it forms a subject studied in the present work. Characterization of activated carbon shows that surface area has an effect although the reactivity of the surface as a result of oxygenated functional groups, e.g. 
carboxylate and phenolate is thought to be significant in the sorption of metal cations. Pore size distribution has been used to describe the internal structures and adsorption capacities of activated carbons [20]. The highly active surface properties of the activated carbon are attributed to the chemical functional groups and the internal surface areas, which typically range from 500 to 3000 $\mathrm{m}^{2} / \mathrm{g}$ [21]. The effect of copper was studied in the adsorption of cyanide onto activated carbon. It was found that the removal capacity was highly improved by the presence of copper [18-21]. It is the aim of this research to use of activated carbon (obtained from cassava peel) $[22,23]$ and alumina impregnated with cooper for obtain catalyst for the removal of cyanide for dilute solutions. The pertinent parameters that influence adsorption such as initial cyanide $\left(\mathrm{CN}^{-}\right)$concentration, agitation time, $\mathrm{pH}$ and temperature were investigated. Adsorption isotherms at three different temperatures (i.e. $283 \mathrm{~K}, 313 \mathrm{~K}, 323 \mathrm{~K}$ ) have been studied. The adsorption data have been interpreted using Freundlich and Langmuir isotherms. Various thermodynamic parameters including the mean energy of adsorption have been calculated.

\section{EXPERIMENTAL}

All reagents used in the experimental work were of analytical grade (E.MERCK)® Argentmetric (largely $\mathrm{AgNO}_{3}$ ) titrations were employed for $\mathrm{CN}$ - determination [8]. Stock solution of cyanide (1000 mg. $\left.\mathrm{L}^{-1}\right)$ was prepared by dissolving Sodium cyanide in distilled water. The concentration range of cyanide prepared from stock solution varied between 10 to $80 \mathrm{mg} . \mathrm{L}^{-1}$.

\subsection{Preparation of Catalysts}

The activated carbon used in this study was prepared for by pyrolysis of cassava peel in presence of chloride zinc (chemical activities) by our research group. Cassava peel from Colombian Cassava cultives were impregnated with aqueous solutions of $\mathrm{ZnCl}_{2}$ following a variant of the incipient wetness method $[22,23]$ with a specific surface area of $1567 \mathrm{~m}^{2} \cdot \mathrm{g}^{-1}$.

One of them was obtained commercial (SasolTM) sample of $\gamma$-alúmina.

\subsubsection{Impregnation}

Catalysts (activated carbon with cooper was labeled $\mathrm{Cu}$-AC and $\gamma$-alúmina with cooper was labeled $\mathrm{Cu}-\mathrm{A}$ ) were formulated using a solution of $\mathrm{Cu}\left(\mathrm{NO}_{3}\right)_{2} \cdot 3 \mathrm{H}_{2} \mathrm{O}(5$ wt. $(\%) \mathrm{Cu})$ as a precursor of the active agent because of its water solubility, lower cost, and lack of poisonous elements. Activated carbons from cassava peel and $\gamma$-alúmina were used as supports. There are two well known methods of loading the metal precursor on the support: incipient wetness impregnation and soaking method. In this case, the second one was used; the activated carbon and $\gamma$-alúmina were soaked in a copper nitrate solution for 8 days under agitation until the equilibrium was reached. The ratio solid/solution (weight base) was equal to 6. The impregnated solids were filtered and scurried during 24 hours. Then, they were dried at $378 \mathrm{~K}$ for 24 hours 12 .

\subsubsection{Thermal Treatment}

The objective of this step is to transform the copper salt (cupric nitrate) in copper oxides, which are the active catalytic agents. The high temperature used descomposes the nitrate releasing nitrogen oxides. The reactor must work in a nitrogen atmosphere to avoid the combustion of the support. The catalysts were treated in the activation reactor, at $830 \mathrm{~K}$ for 24 hours. After that, a nitrogen flow was maintained until the reactor reached room temperature 12 .

\subsection{Characterization}

Nitrogen adsorption-desorption isotherms were performed using an Autosorb-3B (Quantachrome) equipment. Samples of $0.100 \mathrm{~g}$ were oven-dried at $378 \mathrm{~K}$ during 24 hours and outgassed at $473 \mathrm{~K}$ under vacuum for 10 hours. The final pressure was less than $10^{-4}$ mbar. Textural parameters were derived from adsorption data. The specific BET surface area was estimated 15. The specific total pore volume $\left(\mathrm{V}_{\mathrm{T}}\right)$ was determined from the adsorption isotherm at the relative pressure of 0.99 , converted to liquid volume assuming a nitrogen density of $0.808 \mathrm{~g} . \mathrm{cm}^{-3}$. The specific micropore volume $\left(\mathrm{V}_{\mathrm{DR}}\right)$ was determined using the Dubinin-Radushkevich mode 116. The pore size distribution (PSD) was analyzed using the BJH method [17,21-24].

Acidity and basicity determinations of the support were made by titrating the acid sites with a strong basic solution and the basic sites with a strong acid solution, following the protocol detailed by Giraldo et al. [22,23].

The point of charge zero (PZC) of the catalyst were determined for a procedure very similar [24], which are described here. In a beaker were added $0.1 \mathrm{~g}$ of finely ground catalyst in an agate mortar and $20 \mathrm{~mL}$ of a 0.01 $\mathrm{M} \mathrm{KCl-0.004} \mathrm{M} \mathrm{KOH.} \mathrm{The} \mathrm{solution} \mathrm{was} \mathrm{kept} \mathrm{under} \mathrm{con-}$ stant stirring for $48 \mathrm{~h}$. Then, titration was performed with a $0.1 \mathrm{M} \mathrm{HCl}$ solution using a burette and a stream of nitrogen to prevent carbon dioxide from the air is absorbed into the solution and the formation of $\mathrm{CO}_{3}{ }^{-2}$ and $\mathrm{HCO}_{3}{ }^{-1}$. The titrant solution was added slowly $0.1 \mathrm{~mL}$ and was recorded by adding the aggregate volume and $\mathrm{pH}$ of the solution. Furthermore, the evaluation was carried $0.01 \mathrm{M}$ solution of $\mathrm{KCl}-0004 \mathrm{KOH}$ under the same conditions but without catalyst. The PCC of the catalyst was determined by plotting the $\mathrm{pH}$ of the solution against the volume of titrant solution to the solution without 
catalyst and the catalyst solution, the $\mathrm{pH}$ where these two curves intersect corresponds to the PZC. Another way interpret experimental data is to calculate the burden of surface of the catalyst using the equations reported in literature [24], in this case the $\mathrm{pH}$ at which the burden of surface is zero corresponds to the PZC.

Studies of $\mathrm{X}$ ray diffraction (XRD) patterns were recorded at room temperature using a Rigaku diffractometer operated at $30 \mathrm{kV}$ and $20 \mathrm{~mA}$, employing Ni-filtered $\mathrm{Cu} \mathrm{K} \alpha$ radiation $(\lambda=0.15418 \mathrm{~nm})$. The crystalline phases were identified employing standard spectra software.

\subsection{Adsorption Studies}

The adsorption of $\mathrm{CN}^{-}$on activated carbon and $\gamma$-Alumina impregnated with $\mathrm{Cu}$ was studied by batch-technique [9]. The general method used for these studies is described below: A known weight (i.e., $0.5 \mathrm{~g}$ of the $\mathrm{Cu}-$ $\mathrm{AC}$ or $\mathrm{Cu}-\mathrm{A}$ ) was equilibrated with $25 \mathrm{~cm}^{3}$ of the spiked cyanide solution of known concentrations in Pyrex glass flasks at a fixed temperature in a thermostated shaker water bath for a known period of time (i.e. 30 minutes). After equilibrium the suspension was centrifuged in a stoppered tube for 5 minutes at $4500 \mathrm{rpm}$, was then filtered through Whatman 41 filter paper. All adsorption experiments except where the $\mathrm{pH}$ was varied were done at $\mathrm{pH} 7.20$, which was obtained naturally at solution to adsorbent ratio of 50:1. To study the effect of $\mathrm{pH}$, in one set of experiments the $\mathrm{pH}$ of the suspensions was adjusted by using $\mathrm{NaOH} / \mathrm{NH}_{4} \mathrm{OH}$ and $\mathrm{HNO}_{3}$. The $\mathrm{pH}$ of solutions was in the range of 3.0-12. The amount of cyanide adsorbed, " $\mathrm{X}$ " and the equilibrium cyanide concentration in the solution, " $\mathrm{C}_{\mathrm{e}}$ " was always determined volumetrically with standard silver Nitrate solution. Adsorption of cyanide on $\mathrm{Cu}-\mathrm{AC}$ and $\mathrm{Cu}-\mathrm{A}$ was determined in terms of percentage extraction. Amount adsorbed per unit weight of the $\mathrm{Cu}-\mathrm{AC}$ or $\mathrm{Cu}-\mathrm{A}, \mathrm{X} / \mathrm{m}$ was calculated from the initial and final concentration of the solution, Adsorption capacity for the adsorption of cyanide species has been evaluated from the Freundlich and Langmuir adsorption isotherms were studied at three different temperatures (i.e. $283 \mathrm{~K}, 313 \mathrm{~K}, 323 \mathrm{~K}$ ). The cyanide concentration studied was in the range of $10 \mathrm{pmm}$ to $80 \mathrm{ppm}$ for $50: 1$ solution to the catalyst.

\section{RESULTS AND DISCUSSIONS}

\subsection{Characterization}

Nitrogen adsorption-desorption isotherms for the supports and catalysts are shown in Figures 1 and 2. The textural parameters modeled from the adsorption data are summarized in Table $\mathbf{1 .}$

Both catalysts present lower surface area and pore vo- lume compared to that of the corresponding support. This is mainly due to a pore blocking effect, especially micropores, which is evident from the analysis of the uptake at low relative pressures in the adsorption-desorption isotherms for the catalysts compared to the supports. The micropore volume and surface area using activated carbon is higher than that obtained from $\gamma$-alumina, as the total pore volume for both materials.

The isotherms corresponding to both catalysts present

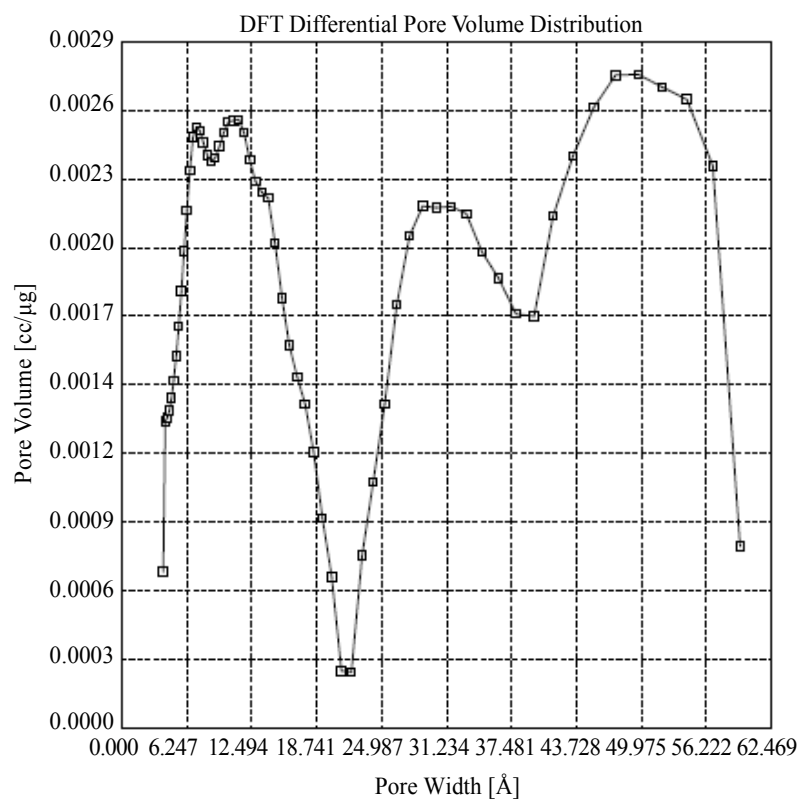

Figure 1. Pore distribution for $\mathrm{Cu}-\mathrm{AC}$.

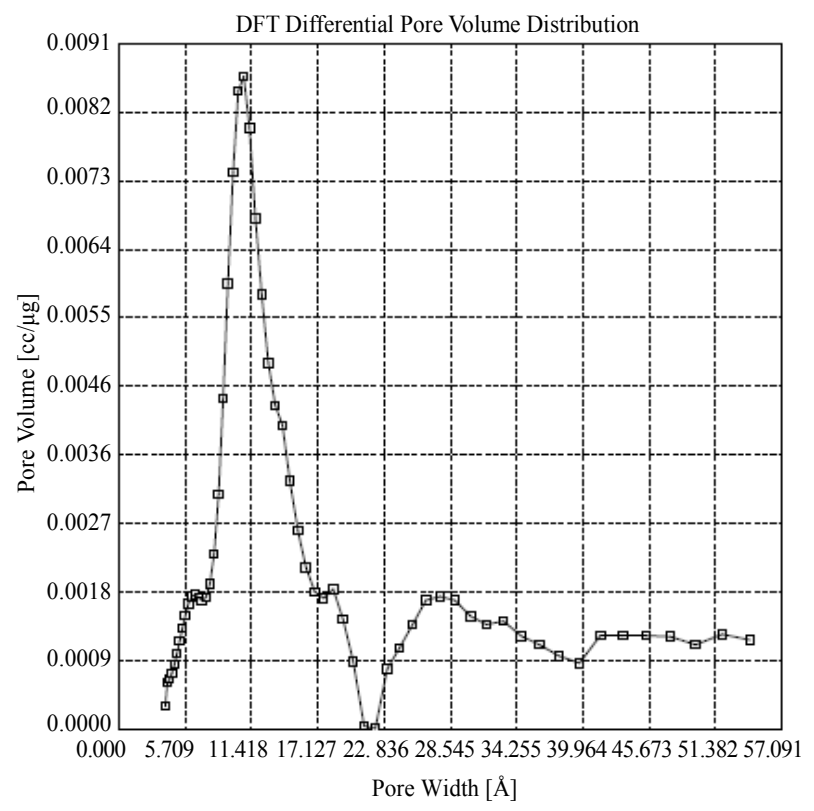

Figure 2. Pore distribution for $\mathrm{Cu}-\mathrm{A}$. 
Table 1. Textural parameters of catalyst.

\begin{tabular}{cccc}
\hline Sample & BET surface area $\left(\mathrm{m}^{2} \cdot \mathrm{g}^{-1}\right)$ & $\begin{array}{c}\text { Pore volume }\left(\mathrm{V}_{\mathrm{T}}\right) \\
\left(\mathrm{cm}^{3} \cdot \mathrm{g}^{-1}\right)\end{array}$ & Specific micropore volume $\left(\mathrm{V}_{\mathrm{DR}}\right)\left(\mathrm{cm}^{3} \cdot \mathrm{g}^{-1}\right)$ \\
\hline $\mathrm{AC}$ & 1567 & 0.6641 & 0.6245 \\
$\mathrm{Cu}-\mathrm{AC}$ & 1245 & 0.5478 & 0.6042 \\
$\gamma$-Alúmina & 245 & 0.2454 & - \\
$\mathrm{Cu}-\mathrm{A}$ & 207 & 0.2087 & - \\
\hline
\end{tabular}

a hysteresis loop. The uptake at high pressure rises significantly for $\mathrm{Cu}-\mathrm{A}$, which indicates a considerable presence of mesoporous. The BJH pore size distribution (Figures 1 and 2) shows important mesoporosity in the range of 40-90 $\AA$ for both catalysts, especially in $\mathrm{Cu}-\mathrm{AC}$, in agreement with its hysteresis loop.

Figures 3 and 4 show the curves obtained in the point of zero charge determinations using the mass titration method. All these results, $\mathrm{pH}$, acidity, basicity and pzc,

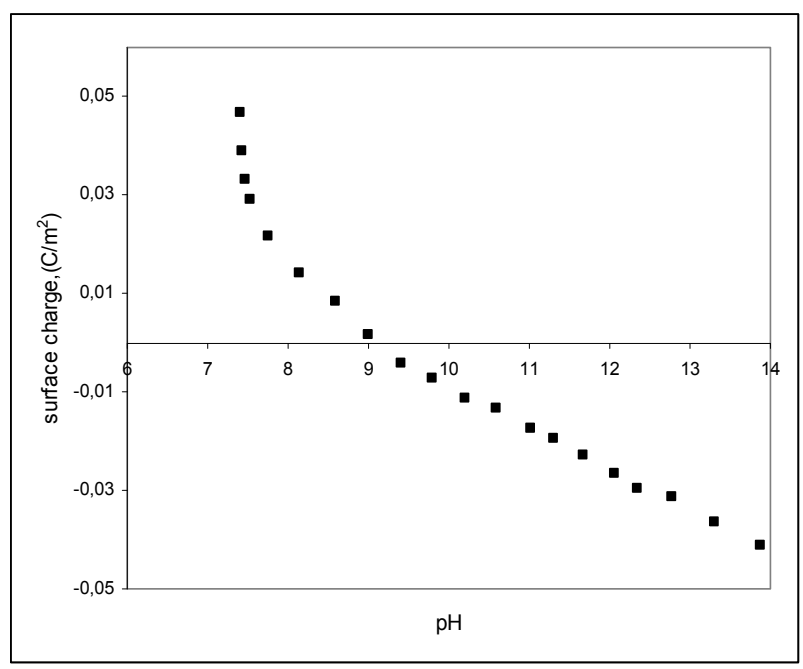

Figure 3. $\mathrm{PZC}$ for $\mathrm{Cu}-\mathrm{A}$ catalyst.

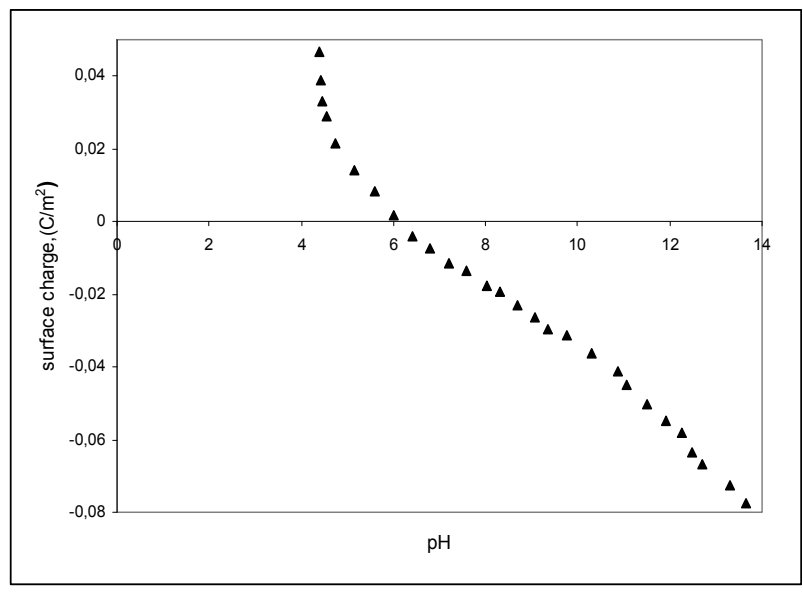

Figure 4. $\mathrm{PZC}$ for $\mathrm{Cu}-\mathrm{AC}$ catalyst. demonstrate that the surface of both supports are strongly basic (Table 2).

The X Ray diffraction patterns for both catalysts, $\mathrm{Cu}$ $\mathrm{AC}$ and $\mathrm{Cu}-\mathrm{A}$ respectively are shown in Figures 5 and $\mathbf{6}$. The profiles obtained show that the main oxidized metal compound corresponds to $\mathrm{CuO}$. The signals of $\mathrm{Cu}_{2} \mathrm{O}$ and $\mathrm{Cu}$ are also present in the spectra, specially the last one. The presence of $\mathrm{CuO}$ was expected because the metal appears as divalent ion in the precursor salt. The reduced species $\left(\mathrm{Cu}^{+}\right.$and $\left.\mathrm{CuO}\right)$ could be produced by the reducing action of the carbon surface during the thermal treatment at high temperatures.

The adsorption of cyanide on the catalyst $\mathrm{Cu}-\mathrm{AC}$ and $\mathrm{Cu}$-A were studied as a function of shaking time in water Bath shaker (Labconco 3535 US), pH, adsorbate concentration and temperature for known cyanide concentration at $313 \mathrm{~K}$. The results are interpreted in terms of percentage adsorption. The variation of $\%$ adsorption with different intervals of time ranging from 2 minutes to 48 hours is illustrated by Figure 7 which shows that the adsorption of cyanide at $25 \mathrm{ppm}$ as well as $50 \mathrm{ppm}$ concentration on $\mathrm{Cu}-\mathrm{AC}$ and $\mathrm{Cu}-\mathrm{A}$ is rapid at $313 \mathrm{~K}$ and equilibrium reached instantaneously after mixing cya-

Table 2. Physicochemical characteristics of the catalyst.

\begin{tabular}{ccccc}
\hline Support & $\mathrm{pH}$ & $\begin{array}{c}\text { Acidity } \\
\left(\mathrm{mmol}^{-1}\right)\end{array}$ & Basicity $\left(\mathrm{mmol.g} \mathrm{g}^{-1}\right)$ & $\mathrm{pH}_{\mathrm{PZC}}$ \\
\hline $\mathrm{Cu}-\mathrm{AC}$ & 8.6 & 0.27 & 0.81 & 9.0 \\
$\mathrm{Cu}-\mathrm{A}$ & 5.8 & 0.20 & 0.45 & 6.0 \\
\hline
\end{tabular}

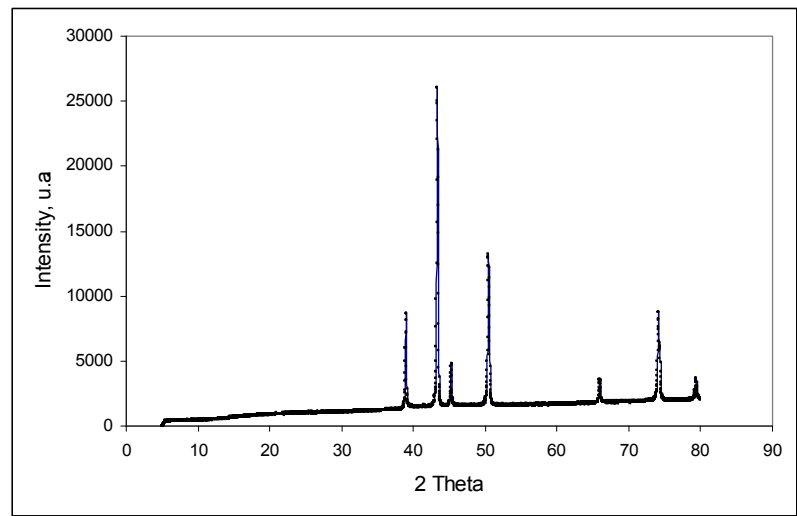

Figure 5. DRX for $\mathrm{Cu}-\mathrm{AC}$ catalys. 


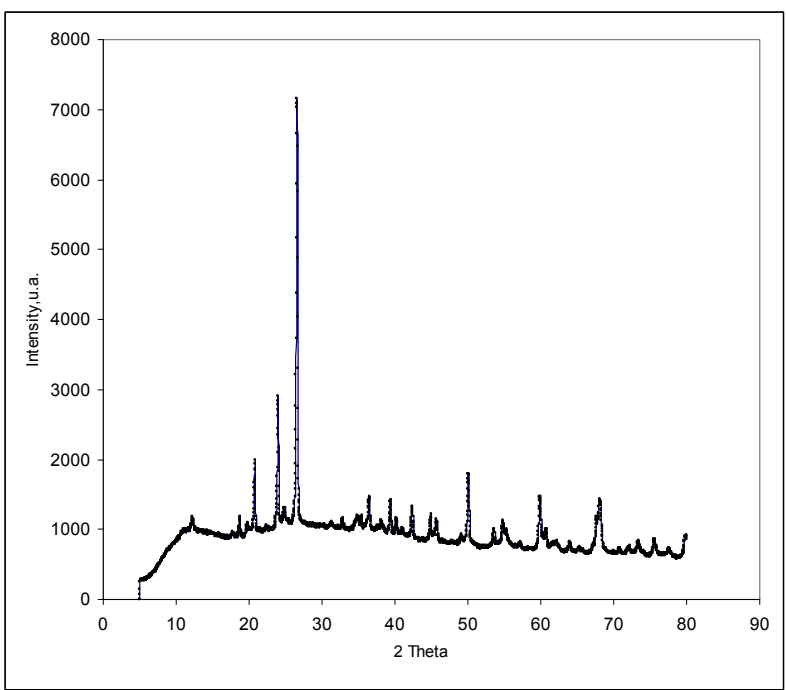

Figure 6. DRX Cu-A catalyst.

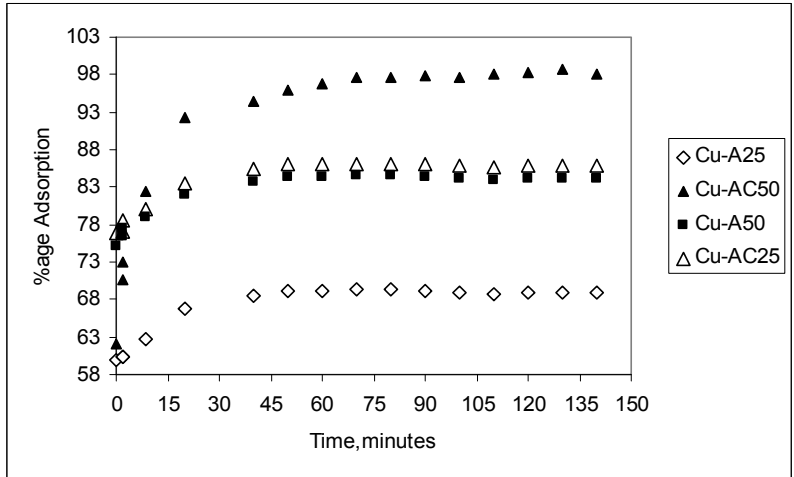

Figure 7. Effect of shaking time \% age Adsorption at $25 \mathrm{ppm}$ and $50 \mathrm{ppm}$ for the synthesized catalyst.

nide solution with the catalyst. However, an equilibriumis reached faster with the catalyst of $\mathrm{Cu}-\mathrm{AC}$ than with $\mathrm{Cu}-\mathrm{A}$; that is associated with the greatest amount of copper that is achieved on the activated carbon adsorb taking into account their surface properties and specific chemical the $\mathrm{PZC}$ allowing $\mathrm{CN}$ ions adsorb more rapidly on the catalyst surface $\mathrm{Cu}-\mathrm{AC}$ on the $\mathrm{Cu}-\mathrm{A}$.

No significant change in \% adsorption values was observed up to 48 hours, which indicates that surface precipitation as well as ion exchange may be the possible adsorption mechanism. Therefore, equilibrium time of 20 minutes was selected for all further studies. The adsorption is $\mathrm{pH}$ dependent, a much greater adsorptive ca pacity for cyanide was observed in neutral solution for both catalyst; moreover it is more higher adsorption capacity for $\mathrm{Cu}-\mathrm{AC}$, i.e., $\mathrm{pH}$ 7- 8.0 (Table 3 and Table 4).

Because when the $\mathrm{pH}$ is reduced, surface charge of the particles becomes increasingly positive and because of the competition of the hydrogen ions for the binding sites,
Table 3. Dependence of absorbance concentration relative to $\mathrm{CN}$ - on $\mathrm{Cu}$-A catalyst at $293 \mathrm{~K}$.

\begin{tabular}{ccccc}
\hline pH & $\begin{array}{c}\text { Amount of } \mathrm{CN}^{-} \\
\text {in taken }\end{array}$ & $\begin{array}{c}\text { Amount of CN- in } \\
\text { sol. At equilibrium }\end{array}$ & Adsount of $\mathrm{CN}^{-}$ & \multirow{2}{*}{ Adsorption } \\
\hline & $(\mathrm{ppm})$ & $(\mathrm{ppm})$ & $(\mathrm{ppm})$ & $(\%)$ \\
2,06 & 20 & 6,48 & 13,52 & 67,60 \\
4,57 & 20 & 5,44 & 14,56 & 72,80 \\
6,54 & 20 & 4,11 & 15,89 & 79,45 \\
7,28 & 20 & 2,13 & 17,87 & 89,35 \\
9,14 & 20 & 4,11 & 15,89 & 79,45 \\
11,34 & 20 & 6,55 & 13,45 & 67,45 \\
12,75 & 20 & 7,76 & 12,24 & 61,20 \\
\hline
\end{tabular}

Table 4. Dependence of absorbance concentration relative to $\mathrm{CN}$ - on $\mathrm{Cu}-\mathrm{AC}$ catalyst at $293 \mathrm{~K}$.

\begin{tabular}{|c|c|c|c|c|}
\hline $\mathrm{pH}$ & $\begin{array}{l}\text { Amount of } \\
\mathrm{CN}^{-} \text {in taken }\end{array}$ & $\begin{array}{l}\text { Amount of } \mathrm{CN}-\text { in } \\
\text { sol. At equilibrium }\end{array}$ & $\begin{array}{l}\text { Amount of } \mathrm{CN}^{-} \\
\text {Adsorbed }\end{array}$ & Adsorption \\
\hline & (ppm) & (ppm) & (ppm) & $(\%)$ \\
\hline 2,06 & 20 & 5,35 & 14,65 & 73,25 \\
\hline 4,57 & 20 & 3,34 & 16,66 & 83,30 \\
\hline 6,54 & 20 & 1,23 & 18,77 & 93,85 \\
\hline 7,28 & 20 & 0,99 & 19,01 & 95,05 \\
\hline 9,14 & 20 & 2,02 & 17,98 & 89,90 \\
\hline 11,34 & 20 & 4,66 & 15,34 & 75,70 \\
\hline 12,75 & 20 & 5,55 & 14,45 & 72,25 \\
\hline
\end{tabular}

metal ions tend to desorbs at low $\mathrm{pH}$ region, as well a small decrease in cyanide adsorption was observed at $\mathrm{pH}$ higher than 9.0. This behavior may be due to the formation of soluble cyanide complexes, which remain in solution as dissolved component. Similarly adsorption of cyanide as a function of its concentration was studied by varying the metal concentration from $10 \mathrm{ppm}$ to $80 \mathrm{pmm}$, $\%$ age adsorption values decreases with increasing metal concentration (Table 5), which suggest that at least two types of phenomena (i.e. adsorption as well ion-exchange) taking place in the range of metal concentration studied, in addition less favorable lattice positions or exchange sites become involved with increasing metal concentration.

The adsorption in aqueous solutions and adsorption isotherms at three different temperatures (i.e. $278 \mathrm{~K}, 298$ $\mathrm{K}, 323 \mathrm{~K}$ ) were obtained by plotting the amount of cya-

Table 5. Dependence of adsorbate concentration relative to $\mathrm{CN}$ - on $\mathrm{Cu}-\mathrm{AC}$ (this catalyst present major adsorption).

\begin{tabular}{ccccc}
\hline $\begin{array}{c}\text { Amount of } \\
\text { Adsorbent } \\
\mathrm{CN}^{-} \text {in taken }\end{array}$ & $\begin{array}{c}\text { Amount of } \\
\mathrm{CN} \text { - taken }\end{array}$ & $\begin{array}{c}\text { Amount of } \\
\mathrm{CN}^{-} \text {in soln. } \\
\text { at Equilibrium }\end{array}$ & $\begin{array}{c}\text { Amount of } \\
\mathrm{CN}^{-} \text {Adsorbed }\end{array}$ & Adsorption \\
\hline $\mathrm{mg}$ & $(\mathrm{ppm})$ & $(\mathrm{ppm})$ & $(\mathrm{ppm})$ & $(\%)$ \\
500 & 5,00 & 2,42 & 2,58 & 51,60 \\
500 & 10,00 & 3,12 & 6,88 & 68,00 \\
500 & 20,00 & 1,41 & 18,52 & 92,60 \\
500 & 40,00 & 15,65 & 30,35 & 75,88 \\
500 & 60,00 & 37,98 & 38,44 & 64,06 \\
500 & 80,00 & 41,09 & 38,91 & 48,63 \\
500 & 100,00 & 54,58 & 45,42 & 45,42 \\
\hline
\end{tabular}


nide adsorbed on $\mathrm{Cu}-\mathrm{A}$ and $\mathrm{Cu}-\mathrm{AC}(\mathrm{mg} / \mathrm{g})$ against metal at equilibrium concentration "Ce" (mg/l). Adsorption of cyanide decreases with increasing temperature. Two models, Langmuir and Freundlich equations, were used to describe experimental data for adsorption isotherms.

The linear form of the Freundlich isotherm model is given by the following relation:

$$
\log \mathrm{x} / \mathrm{m}=\log \mathrm{K}_{\mathrm{F}}+1 / \mathrm{n} \log \mathrm{Ce}
$$

where $\mathrm{x} / \mathrm{m}$ is the amount adsorbed at equilibrium $(\mathrm{mg} / \mathrm{g})$, $\mathrm{Ce}$ is the equilibrium concentration of the adsorbate $(\mathrm{mg} / \mathrm{l})$, and $\mathrm{K}_{\mathrm{F}}$ and $1 / \mathrm{n}$ are the Freundlich constants related to adsorption capacity and adsorption intensity respectively, of the sorbent. The values of $K_{F}$ and $1 / n$ can be obtained from the intercept and slope respectively, of the linear plot of experimental data of $\log \mathrm{X} / \mathrm{m}$ versus $\log$ Ce. The linear form of the Langmuir isotherm model can be represented by the following relation:

$$
\mathrm{Ce} / \mathrm{x} / \mathrm{m}=1 / \mathrm{K}_{\mathrm{L}} \mathrm{Vm}+\mathrm{Ce} / \mathrm{Vm}
$$

where $\mathrm{Vm}$ and $\mathrm{K}_{\mathrm{L}}$ are the Langmuir constants related to the maximum adsorption capacity and the energy of adsorption, respectively. These constants can be evaluated from the intercept and slope of the linear plot of experimental data of $\mathrm{Ce} / \mathrm{X} / \mathrm{m}$ versus $\mathrm{Ce}$. The Freundlich and Langmuir adsorption isotherms are shown in Figure 3 and Figure 4 (the isotherms linearizated not shown here). The related parameters of Langmuir and Freundlich models are summarized in Table 6. The results reveal that both the Langmuir isotherm model adequately describes better the adsorption data (See Figure 8).

Calculations of thermodynamic parameters:

Thermodynamic parameters such as Gibbs free energy $\Delta \mathrm{G}^{\circ}(\mathrm{kJ} / \mathrm{mol})$, change in enthalpy $\Delta \mathrm{H}^{\circ}(\mathrm{kJ} / \mathrm{mol})$ and change in entropy $\Delta \mathrm{S}^{\circ}\left(\mathrm{J}_{\mathrm{K}} \mathrm{K}^{-1} \mathrm{~mol}^{-1}\right)$ for cyanide adsorption were calculated from the distribution constant $\mathrm{K}$ [10] by using the following relations:

$$
\begin{gathered}
\Delta \mathrm{G}^{\circ}=-\mathrm{RT} \ln \mathrm{K} \\
\Delta \mathrm{G}^{\circ}=\Delta \mathrm{H}^{\circ}-
\end{gathered}
$$

and

$$
\mathrm{K}=-\Delta \mathrm{H}^{\circ} / \mathrm{RT}+\text { Constant }
$$

Tables 7 and $\mathbf{8}$ show the values of thermodynamics parameters $\Delta \mathrm{H}^{\circ}, \Delta \mathrm{S}^{\circ}, \Delta \mathrm{G}^{\circ}$ for $\mathrm{Cu}-\mathrm{AC}$ and $\mathrm{Cu}-\mathrm{A}$ catalyst synthesized. The positive value of $\Delta \mathrm{H}^{\circ}=6.234 \mathrm{~kJ} / \mathrm{mole}$ for $\mathrm{Cu}-\mathrm{AC}$ and $4.897 \mathrm{~kJ} / \mathrm{mole}$, which is calculated from Eq.5 and Figure 5, confirms the endothermic nature of the overall adsorption process. The positive value of $\Delta \mathrm{S}^{\circ}$ suggests increased randomness at the solid/solution interface with some structural change in the adsorbate and adsorbent and also affinity of the $\mathrm{Cu}-\mathrm{AC}$ and $\mathrm{Cu}-\mathrm{A}$ towards $\mathrm{CN}^{-}$; the values more highest of entropy indicate spontaneous process. A negative value of $\Delta \mathrm{G}^{\circ}$ indicates
Table 6. Parameters of Lagmuir and Freundlich for adsorption of cyanide.

\begin{tabular}{ccccccc}
\hline & Langmuir & & \multicolumn{3}{c}{ Freundlich } \\
\hline $\mathrm{Q}_{0}$ & $\mathrm{~K}$ & $\mathrm{R}^{2}$ & $\mathrm{~K}_{\mathrm{f}}$ & $\mathrm{n}$ & $\mathrm{R}^{2}$
\end{tabular}

Alumina 221,9725 0,018648 0,99835 7,431714 1,477998 0,99653

$\begin{array}{ccccccc}\text { Activated } & 226,7673 & 0,029620 & 0,99781 & 11,98697 & 1,628459 & 0,99330\end{array}$

Cu-A $\quad 317,2252 \quad 0,041956 \quad 0,99700 \quad 22,77397 \quad 1,759936 \quad 0,98713$

$\begin{array}{llllll}\text { Cu-Ac } \quad 297,2679 & 0,164927 & 0,99646 & 58,15241 & 2,573350 & 0,97419\end{array}$

Table 7. Values of thermodynamic data for Adsorption of $\mathrm{CN}$ on $\mathrm{Cu}-\mathrm{AC}$.

\begin{tabular}{cccc}
\hline $\begin{array}{c}\text { Temperature } \\
\mathrm{K}\end{array}$ & $\begin{array}{c}\Delta \mathrm{H}^{\circ} \\
\mathrm{kJ} / \mathrm{mol}\end{array}$ & $\begin{array}{c}\Delta \mathrm{G}^{\circ} \\
\mathrm{kJ} / \mathrm{mol}\end{array}$ & $\begin{array}{c}\Delta \mathrm{S}^{\circ} \\
\mathrm{J} / \mathrm{K} . \mathrm{mol}\end{array}$ \\
\hline 278 & 6.234 & -8.856 & 0.0543 \\
298 & 6.234 & -6.636 & 0.0432 \\
323 & 6.234 & -12.666 & 0.0585 \\
\hline
\end{tabular}

Table 8. Values of thermodynamic data for Adsorption of $\mathrm{CN}$ on $\mathrm{Cu}-\mathrm{A}$.

\begin{tabular}{cccc}
\hline $\begin{array}{c}\text { Temperature } \\
\mathrm{K}\end{array}$ & $\begin{array}{c}\Delta \mathrm{H}^{\circ} \\
\mathrm{kJ} / \mathrm{mol}\end{array}$ & $\begin{array}{c}\Delta \mathrm{G}^{\circ} \\
\mathrm{kJ} / \mathrm{mol}\end{array}$ & $\begin{array}{c}\Delta \mathrm{S}^{\circ} \\
\mathrm{J} / \mathrm{K} \cdot \mathrm{mol}\end{array}$ \\
\hline 278 & 4.897 & -6.863 & 0.0423 \\
298 & 4.897 & -6.963 & 0.0398 \\
323 & 4.897 & -10.183 & 0.0467 \\
\hline
\end{tabular}

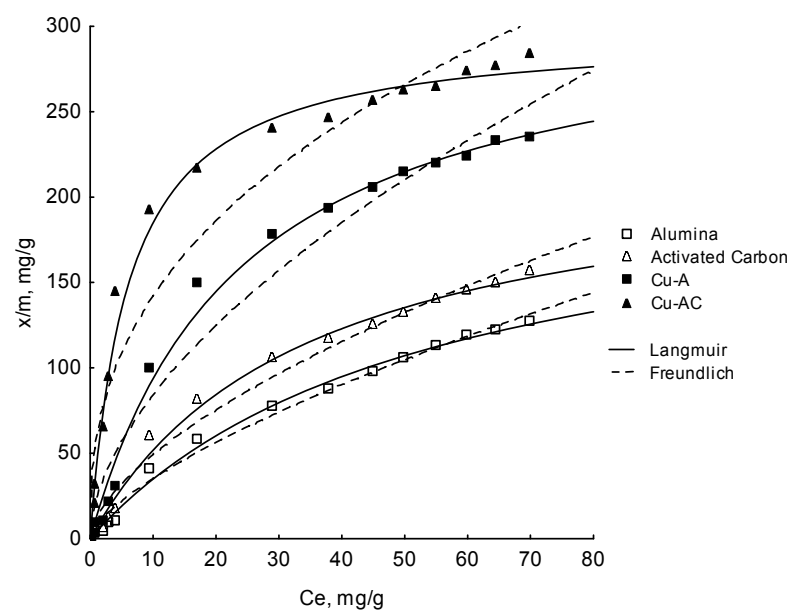

Figure 8. Langmuir and Freundlich models adjustment at 298 K.

the feasibility and spontaneity of the adsorption process, where higher negative value reflects a more energetically favorable adsorption process. The process of adsorption $\mathrm{Cu}-\mathrm{AC}$ is more favorable. 


\section{CONCLUSIONS}

Keeping the adsorptive nature of $\mathrm{Cu}-\mathrm{AC}$ and $\mathrm{Cu}-\mathrm{A}$ in view it is felt desirable to select batch adsorption process for removal of Cyanide from the industrial wastewater using activated carbon and $\gamma$-alumina. The main advantages of the procedure are:

1) The cost of starting materials for obtaining the catalyst is low and easily available in country.

2) Ease and simplicity of preparation of the catalyst due to non-corrosive and non-poisonous nature of activated carbon and alumina.

3) Rapid attainment of phase equilibration and good enrichment as well fitting of adsorption data with Langmuir isotherms.

4) The positive value of $\Delta \mathrm{H}^{\circ}$ and negative values of $\Delta \mathrm{G}^{\circ}$ indicate the endothermic and spontaneous nature of the adsorption process.

\section{ACKNOWLEDGEMENTS}

The authors wish to thank the Master Agreement established between Universidad de los Andes and Universidad Nacional de Colombia, and the Memorandum of Understanding between Departments of Chemistry of both Universities. Additionally, special thanks to Fondo Especial de la Facultad de Ciencias and Proyecto Semilla of Universidad de los Andes for the partial financial of this research.

\section{REFERENCES}

[1] Abell, M.L. and Barselton, P.J. (1974) The maple V handbook. AP Professional, New York.

[2] Contescu, C., Jagiello, J. and Schwarz, J.A. (1995) Proton affinity distributions: A scientific basis for the design and construction of supported metal catalysts. Preparation of Catalysts VI, Scientific Bases for the Preparation of Heterogeneous Catalysts, Elsevier Science, New York.

[3] Cooper, D. and Plane, A.R. (1966) Cyanide complexes of copper with ammonia and ethylenediamine. Inorganic Chemistry, 5, 1677-1681.

[4] Gupta, A., Johnson, E.F. and Schlossel, R.H. (1987) Investigation into the ion exchange of the cyanide complexes of Zinc(II), Cadmium(II), and Copper(I) Ions. Industrial Engineering Chemistry Research, 26, 588-597.

[5] Hogfeldt, E. (1982) Stability constants of metal-ion complexes: Part A: Inorganic ligands, Pergamon Press, Oxford.

[6] Riley, T.C. and Semmens, J.M. (1994) Recovery of cadmium and cyanide using a combination of ion exchange and membrane extraction. Plating and Surface Finishing, 81, 46-54.

[7] Tan, T.C. and Teo, W.K. (1987) Destruction of cyanides by thermal hydrolysis. Plating and Surface Finishing, 74, 70-76.
[8] Tien, C. (1994) Adsorption calculations and modeling. Butterworth-heinemann series in chemical engineering, Butterworth Heinemann, Boston.

[9] Wedl, A.G. and Fulk, J.D. (1991) Cyanide destruction in plating sludges by hot alkaline chlorination. Metal Finish, 89, 33-38.

[10] Gupta, C.G. and Murkherjee, T.K. (2001) Hydrometallurgy in extraction process, CRC press, Florida.

[11] Zhou, C.D. and Chin, D.T. (1994) Continuous electrolytic treatment of complex metal cyanides with a rotating barrel plater as the cathode and a packed bed as the anode. Plating and Surface Finishing, 81, 70-81.

[12] Gill, J.B., Gans, P., Dougal, J.C. and Johnson, L.H. (1991) Cyano and thiocyano complexation in solutions of noble metals, Reviews in Inorganic Chemistry, 11, 177-182.

[13] Bhakta, D., Shukla, S.S. and Margrave, L.J. (1992) A novel photocatalytic method for detoxification of cyanide wastes. Environmental Science \& Technology, 26, 625 634.

[14] Bhargava, S., Tardío, J., Prasad, J., Föger, K., Akolekar, D. and Grocott, S. (2006) Wet oxidation and catalytic wet oxidation. Industrial \& Engineering Chemical Research, 45, 1221-1234.

[15] Lei, L., Hu, X., Chen, G., Porter, J.F. and Yue, P.L. (2000) Wet air oxidation of desizing wastewater from textile industry. Industrial \& Engineering Chemical Research, 39, 2896-2905.

[16] Mantzavinos, D., Hellenbrand, R., Livingston, A.G. and Metcalfe, I.S. (1996) Catalytic wet air oxidation of polyethylene glycol. Applied Catalysis B: Environmental, 11, 99-107.

[17] Kolaczkowski, S.T., Plucinski, P., Beltran, F.J., Rivas, F. J., and Mc Lurgh, D.B. (1999) Wet air oxidation: A review of process technologies and aspects in reactor design, Chemical Engineering Journal, 73, 143-152.

[18] Luck, F. (1999) Wet air oxidation: Past, present and future. Catalysis Today, 53, 81-89.

[19] Pintar, A. (2003) Catalytic process for the purification of drinking water and industrial effluents. Catalysis Today, 77, 451-462.

[20] Fortuny, A., Bengoa, C., Font, J., Catells, F. and Fabregat, A. (1999) Water pollution abatement by catalytic wet air oxidation in a trickle bed reactor, Catalysis Today, 53, 107-112.

[21] Deiana, A.C., Granados, D., Petkovic, L.M., Sardella, M. F. and Silva, H.S. (2004) Use of grape must binder to obtain activated carbon briquettes. Brazilian Journal of Chemical Engineering, 21, 585-592.

[22] Moreno-Piraján, J.C. and Giraldo, L. (2010) Study of activated carbons by pyrolysis of cassava peel in the presence of chloride zinc. Journal of Analytical and Applied and Pyrolysis, 87(2), 288-290.

[23] Moreno-Piraján, J.C. and Giraldo, L. (2010) Adsorption of copper from aqueous solution by activated carbons obtained by pyrolysis of cassava peel. Journal of Analytical Applied and Pyrolysis, 7(2), 188-193.

[24] Rodríguez-Reinoso, F. (1998) The role of carbon materials in heterogeneous catalysis, Carbon, 36, 159-164. 